\title{
Brief
}

\section{Effect of gender on bridging to transplantation and posttransplantation survival in patients with left ventricular assist devices}

\author{
Jeffrey A. Morgan, MD, Alan D. Weinberg, MS, Karen W. Hollingsworth, BS, Margaret R. Flannery, ANP, \\ Mehmet C. Oz, MD, and Yoshifumi Naka, MD, PhD, New York, NY
}

From the Division of Cardiothoracic Sur-
gery, College of Physicians and Surgeons,
Columbia University, New York, NY.

Received for publication May 12, 2003; accepted for publication May 16, 2003.

Address for reprints: Yoshifumi Naka, MD, $\mathrm{PhD}$, Columbia University, College of Physicians and Surgeons, 177 Fort Washington Ave, Milstein Hospital 7GN-435, New York, NY 10032 (E-mail: yn33@ columbia.edu).

J Thorac Cardiovasc Surg 2004;127:1193-5

$0022-5223 / \$ 30.00$

Copyright $\odot 2004$ by The American Association for Thoracic Surgery

doi:10.1016/S0022-5223(03)00801-8

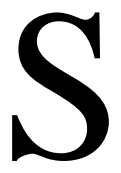

tudies have demonstrated sex differences in survival after various cardiac procedures, with superior survival for male over female patients. ${ }^{1}$ This might be due to a lower threshold to diagnose and aggressively treat heart disease in male patients, resulting in female patients presenting with more advanced pathology and systemic manifestations. ${ }^{2}$ This study was designed to analyze our bridge-to-transplant experience since the beginning of our program. Our primary goal was to determine the effect of sex on survival while on support, rates of successful bridging to transplantation, and posttransplantation survival.

\section{Patients and Methods}

We retrospectively reviewed our experience with Thoratec Heartmate assist devices from August 1990 through September 2002. One hundred ninety-one (80.9\%) male patients and 45 $(19.1 \%)$ female patients underwent implantation. This included 52 pneumatic (40 male and 12 female patients), 17 dual-lead vented electric (15 male and 2 female patients), and 167 single-lead vented electric (136 male and 31 female patients) devices. Preimplantation left ventricular assist device (LVAD) scores, determined on the basis of a patient's presenting degree of clinical stability and shown to correlate with survival on LVAD support in multivariate analysis, were calculated for male and female patients. ${ }^{3}$ The study was performed in accordance with institutional guidelines.

Data were represented as frequency distributions and percentages. Values of continuous variables were expressed as means \pm SD. Continuous variables were compared by using independent samples $t$ tests, whereas categoric variables were compared by using $\chi^{2}$ tests. Kaplan-Meier analysis was used to calculate long-term survival. Significant predictors of survival were identified by using multivariate Cox proportional hazard models. All data were analyzed with SPSS 11.5 software.

\section{Results}

Demographics. Clinical characteristics of male and female patients are outlined in Table 1. There was no significant difference in age, race, or cause of heart failure $(P=$ not significant). Male patients had a significantly higher body surface area than female patients $\left(2.0 \pm 0.2\right.$ vs $\left.1.8 \pm 0.2 \mathrm{~kg} / \mathrm{m}^{2}, P<.001\right)$. LVAD implantation scores were significantly higher for female patients than male patients $(6.4 \pm 3.1$ vs $4.2 \pm 3.2, P=.020)$. Median support time was similar between the groups (51.5 days [0-541 days] for male patients and 46.0 [0-397 days] for female patients, $P=.412$ ).

Survival on LVAD and transplantation rate. Survival on LVAD support was significantly higher for male patients than for female patients $(78.5 \%[\mathrm{n}=150]$ vs $62.2 \%$ [n $=28]$, $P=.022$ ). Successful bridging to transplantation was also significantly higher for male patients than for female patients $(72.8 \%[\mathrm{n}=139]$ vs $57.8 \%[\mathrm{n}=26], P=.048)$.

Posttransplantation survival. Male patients demonstrated significantly improved posttransplantation survival, with actuarial survival at 1,3 , and 5 years of $90.4 \%, 86.6 \%$, and $85.2 \%$, respectively, versus $87.8 \%, 74.3 \%$, and $50.9 \%$, respectively, for female patients $(P=$ 


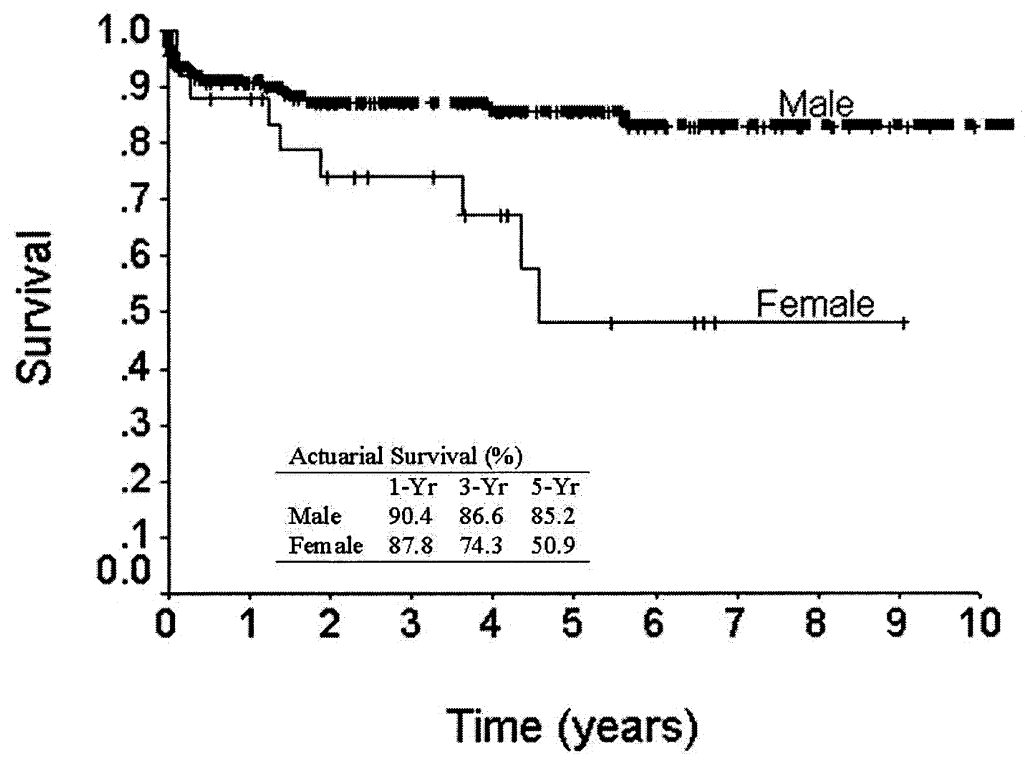

$\log \operatorname{Rank} p=.010$

Figure 1. Posttransplantation survival for male and female patients.

TABLE 1. Clinical characteristics of male and female LVAD recipients

\begin{tabular}{lccr}
\hline & $\begin{array}{c}\text { Male } \\
\text { patients }\end{array}$ & $\begin{array}{c}\text { Female } \\
\text { patients }\end{array}$ & $\begin{array}{c}\boldsymbol{P} \\
\text { value }^{*}\end{array}$ \\
\hline Mean age $(\mathrm{y})$ & $50.2 \pm 13.4 \dagger$ & $47.1 \pm 15.3$ & .110 \\
Race & $147(77.0 \%) \ddagger$ & $33(73.3 \%)$ & .607 \\
$\quad$ White & $28(14.7 \%)$ & $10(22.2 \%)$ & .214 \\
$\quad$ African American & $16(8.4 \%)$ & $2(8.9 \%)$ & .371 \\
$\quad$ Other & $107(56.0 \%)$ & $27(60.0 \%)$ & .955 \\
Cause & $73(38.2 \%)$ & $15(33.3 \%)$ & .242 \\
CAD & $11(5.8 \%)$ & $3(6.7 \%)$ & .326 \\
ICM & $2.0 \pm 0.2$ & $1.8 \pm 0.2$ & .001 \\
Other & $6.4 \pm 3.1$ & $4.2 \pm 3.2$ & .020 \\
BSA (kg/m $\left.{ }^{2}\right)$ & & & \\
LVAD score & $15(7.9 \%)$ & $3(6.7 \%)$ & .781 \\
Infection & $13(6.8 \%)$ & $3(6.7 \%)$ & .931 \\
$\quad$ Drive line & $8(4.2 \%)$ & $2(4.4 \%)$ & .811 \\
Pocket & $36(18.8 \%)$ & $8(17.8 \%)$ & .947 \\
Pump & $5(2.6 \%)$ & $0(0.0 \%)$ & .173 \\
Any &
\end{tabular}

$\overline{C A D}$, Coronary artery disease; ICM, idiopathic cardiomyopathy; $B S A$, body surface area.

${ }^{*} P$ value from independent samples $t$ test.

tMean \pm SD.

$\ddagger$ ‡absolute number (percentage).

.010, Figure 1). However, when comparing male and female patients with similar LVAD implantation scores, there was no significant difference in survival ( $P=$ not significant).

Predictors of survival. For univariate analysis, significant predictors of survival included sex $(P=.001)$, cause of heart failure
( $P=.003$ for idiopathic cardiomyopathy and $P=.048$ for other), and LVAD score $(P<.001)$, with a trend toward significance in age $(P=.080)$.

The only significant predictor of overall survival in multivariate analysis was LVAD score (odds ratio, 1.214; 95\% confidence interval, 1.119-1.316; $P<.001)$. Patients with low LVAD implantation scores (0-4) demonstrated improved survival over patients with medium scores (5-7), whose survival was superior to that of patients with high scores $(8-10 ; P<.001)$. Sex was not an independent predictor of survival (odds ratio, 0.724; 95\% confidence interval, 0.641-0.852; $P=.124)$.

\section{Discussion}

In our study male patients demonstrated superior survival while receiving mechanical assistance, a higher rate of successful bridging to transplantation, and improved survival after transplantation. LVAD preimplantation scores were significantly higher for female patients, indicating that female patients presented in a more advanced state of heart failure. This is consistent with studies that have demonstrated a significant delay in the preliminary suspicion, performance of diagnostic studies, and therapeutic intervention for women with heart failure. ${ }^{4,5}$ The multivariate analysis supports the notion that higher LVAD scores in female patients and not sex in and of itself accounted for inequities in outcome between male and female patients. Furthermore, after adjustment for LVAD score, there was no significant difference in outcome between the sexes. Additional evaluation of the causes for disproportionate survival between male and female patients is warranted.

Limitations of this study include those related to a retrospectively performed analysis. Data were obtained by means of chart review, which is limited by access and accuracy of the data. Additionally, data from our overall institutional experience were 
evaluated, which included pneumatic, dual-lead vented electric, and single-lead vented electric devices, although there have been changes in criteria for device implantation, selection of candidates, and the devices themselves. However, we pursued this approach because of the relatively small number of patients in each individual device category and the lack of statistical power and because the criteria for device implantation have always been similar for male and female patients.

\section{References}

1. Steingart RM, Packer M, Hamm P, Coglianese ME, Gersh B, Geltman EM, et al. Sex differences in the management of coronary artery disease. Survival and Ventricular Enlargement Investigators. $N$ Engl J Med. 1991;325(4):226-30.

2. Ayanian JZ, Epstein AM. Differences in the use of procedures between women and men hospitalized for coronary heart disease. $N$ Engl J Med. 1991;325(4):221-5.

3. Rao V, Oz MC, Flannery MA, Catanese KA, Argenziano M, Naka Y. Revised screening scale to predict survival after insertion of a left ventricular assist device. J Thorac Cardiovasc Surg. 2003;125(4):85562.

4. Roger VL, Farkouh ME, Weston SA, Reeder GS, Jacobsen SJ, Zinsmeister AR, et al. Sex differences in evaluation and outcome of unstable angina. JAMA. 2000;283(5):646-52.

5. Mosca L, Manson JE, Sutherland SE, Langer RD, Manolio T, BarrettConnor E. Cardiovascular disease in women: a statement for healthcare professionals from the American Heart Association Writing Group. Circulation. 1997;96(7):2468-82.

\section{Assessment of coronary flow reserve with a Doppler guide wire in children with tetralogy of Fallot before and after surgical operation}

Kentaro Toiyama, MD, ${ }^{a}$ Isao Shiraishi, MD, ${ }^{a}$ Tatsujiro Oka, MD, ${ }^{a}$ Ayumi Kawakita, MD, ${ }^{a}$ Naoya Iwasaki, MD, ${ }^{a}$ Toshikatsu Tanaka, MD, ${ }^{a}$ Koichi Sakata, MD, ${ }^{a}$ Toshiyuki Itoi, MD, ${ }^{a}$ Keisuke Shuntoh, MD, ${ }^{\mathrm{b}}$ Masaaki Yamagishi, MD, ${ }^{\mathrm{b}}$ and Kenji Hamaoka, MD, ${ }^{a}$ Kyoto, Japan

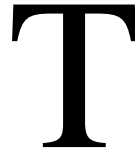
etralogy of Fallot (TOF) is one of the most common cyanotic congenital heart diseases in childhood. Before surgical repair, patients with TOF are exposed to right ventricular (RV) pressure overload, which induces RV hypertrophy. Although cardiac hypertrophy has been shown to induce impaired coronary microcirculation and cardiac dysfunction in adults, ${ }^{1}$ it is uncertain whether RV hypertrophy induces impaired coronary microcirculation in patients with TOF. The purpose of this study was to evaluate the relationship between the $\mathrm{RV}$ pressure overload and the coronary flow reserve (CFR) in TOF and to search for the best way to prevent life-threatening events.

\section{Methods}

The study population consisted of 14 patients with TOF ( 8 male and 6 female, Table 1). They were divided into three groups: preoperative $(n=4)$, early postoperative $(n=6)$, and late post-

\footnotetext{
From the Departments of Pediatrics ${ }^{\mathrm{a}}$ and Pediatric Cardiovascular Surgery, Children's Research Hospital, Kyoto Prefectural University of Medicine, Kyoto, Japan.

Received for publication Jan 7, 2003; accepted for publication June 19, 2003.

Address for reprints: Kenji Hamaoka, MD, Department of Pediatrics, Children's Research Hospital, Kyoto Prefectural University of Medicine, Kawaramachi-Hirokoji, Kamigyo, Kyoto, Japan 602-8566 (E-mail: khamaoka@koto.kpu-m.ac.jp).

J Thorac Cardiovasc Surg 2004;127:1195-7

$0022-5223 / \$ 30.00$

Copyright $\odot 2004$ by The American Association for Thoracic Surgery doi:10.1016/j.jtcvs.2003.06.013
}

\section{TABLE 1. Patient characteristics}

\begin{tabular}{lccc}
\hline Groups & $\begin{array}{c}\text { Preoperative } \\
(\mathbf{n}=\mathbf{4})\end{array}$ & $\begin{array}{c}\text { Early } \\
\text { postoperative } \\
(\mathbf{n = 6 )}\end{array}$ & $\begin{array}{c}\text { Late } \\
\text { postoperative } \\
(\mathbf{n}=\mathbf{4})\end{array}$ \\
\hline Age (y) & $1.25 \pm 0.17$ & $2.56 \pm 0.83$ & $12.9 \pm 2.99$ \\
Sex (male/female) & $2: 2$ & $2: 4$ & $4: 0$ \\
RV pressure (mm Hg) & $93.3 \pm 9.24$ & $49.4 \pm 16.2^{*}$ & $53.0 \pm 11.4^{*}$ \\
PA pressure (mm Hg) & $14.7 \pm 5.7$ & $20.7 \pm 4.0$ & $20.3 \pm 7.8$ \\
RV-PA pressure & $78.7 \pm 9.23$ & $26.2 \pm 18.1^{*}$ & $32.8 \pm 8.42^{*}$ \\
$\quad$ gradient (mm Hg) & & $1.14 \pm 0.34$ & $11.0 \pm 2.01$ \\
$\begin{array}{c}\text { Interval from } \\
\quad \text { operation (y) }\end{array}$ & - & & \\
Pulmonary & & & \\
$\quad$ insufficiency & - & &
\end{tabular}

Data are presented as mean \pm SD. $P A$, Pulmonary artery; \pm , slight regurgitation; + , mild regurgitation.

${ }^{*} P<.05$ versus preoperative value.

operative $(n=4)$. After the radical operation, the RV pressure of these patients improved significantly. Echocardiographic examination after the surgical repair revealed mild to moderate pulmonary regurgitation with mild RV dilatation. The control patients consisted of 16 age-matched patients with Kawasaki disease who had shown normal coronary arteries and normal ventricular function on angiography. ${ }^{2,3}$ They were divided into two groups: younger than 6 years for the preoperative and the early postoperative groups and 6 to 16 years old for the late postoperative group. The Doppler guide wire used in this study was a flexible, 0.018-inch guide wire with a 12-MHz piezoelectric ultrasound transducer (FloWire; Cardiometrics Inc, Mountain View, Calif). Blood flow velocity was 